\section{RMD
Open}

Rheumatic \&

Musculoskeletal Diseases

\title{
Characteristics of Sjögren's syndrome associated with rheumatoid arthritis
}

\author{
Nolan Hassold (D) , ${ }^{1}$ Raphaele Seror (D) , ${ }^{1}$ Xavier Mariette (D) , ${ }^{1,2}$ \\ Gaetane Nocturne ${ }^{1,3}$
}

To cite: Hassold N, Seror R, Mariette X, et al. Characteristics of Sjögren's syndrome associated with rheumatoid arthritis. RMD Open 2022;8:e002234. doi:10.1136/ rmdopen-2022-002234

Accepted 25 January 2022
D Check for updates

\section{(c) Author(s) (or their} employer(s)) 2022. Re-use permitted under CC BY-NC. No commercial re-use. See rights and permissions. Published by BMJ.

1Department of Rheumatology, Hôpital Bicêtre, Le KremlinBicetre, France

${ }^{2}$ Université Paris-Sud, Center for Immunology of Viral Infections and Auto-immune Diseases (IMVA), Institut pour la Santé et la Recherche Médicale (INSERM) UMR 1184, Université ParisSaclay, Le Kremlin Bicêtre, France

${ }^{3}$ Center for Immunology of Viral Infections and Autoimmune Diseases, Le Kremlin-Bicêtre, France

\section{Correspondence to}

Dr Nolan Hassold;

nolan.hassold-rugolino@aphp.fr
Sjögren Syndrome (SS) classically associates sicca syndrome, pain and asthenia. Systemic manifestations may develop with potentially severe organ damage including pulmonary, neurological, renal involvement and lymphoma. ${ }^{12}$ SS can be associated with rheumatoid arthritis (RA). Despite this frequent association, few studies have investigated differences between primary Sjögren syndrome (pSS) and SS associated with $\mathrm{RA}(\mathrm{SS} / \mathrm{RA}) .{ }^{34}$

We have conducted a retrospective single-centre case-controls study. Patients were identified in the Paris-Saclay cohort, a prospectively collected database. Cases were patients fulfilling both ACR/EULAR 2016 criteria for SS and ACR 2010 criteria for RA and followed between 2000 and 2019. For each case, two controls from our local pSS cohort were randomly assigned and matched on disease duration. Disease activity was assessed using the EULAR Sjögren's Syndrome Disease Activity Index $(\text { ESSDAI })^{5}$ and ESSDAI cumulative score (Cumulative ESSDAI). The latter was calculated considering for each domain, the highest value reached by the patient during his/her follow-up. SS/RA and pSS patients were compared using a Chi-square test for non-normal binary variables and MannWhitney-Wilcoxon test for non-normal numeric variables. The $p$ was retained as significant in the statistical analyses if $<0.05$.

Sixty-two SS/RA patients were compared with 124 pSS patients (table 1). There were more women among the pSS group $(\mathrm{p}=0.03)$. We observed a higher disease activity in the SS/RA group when considering ESSDAI and cumulative ESSDAI. We also performed analyses excluding joint involvement: there was no more difference between the two groups, which reflects the weight of the articular domain in the activity of the disease in the SS/RA group. There was higher prevalence of arthralgia and arthritis in the SS/RA group. Pulmonary involvement was also significantly more frequent in SS/RA group; 9/62 (14.5\%) patients (six interstitial lung disease (ILD): 4 non-specific interstitial pneumonia (NSIP) and two non-specific ILD), 1 bronchiectasis, 1 bronchial disorder and one pulmonary cysts) were compared with $7 / 123$ $(5.7 \%)$ patients in the pSS group (3 ILD: 2 NSIP and one non-specific ILD, 3 bronchiectasis and one obstructive bronchial disorder). pSS patients presented more skin or vaginal dryness and parotid gland enlargement. We found higher ESR levels and higher rate of RF positivity in the SS/ RA group compared with pSS. Even though numerically higher in the pSS group, the frequency of lymphoma did not significantly differ between groups $(\mathrm{p}=0.267)$. There was no difference between the two groups on the other parameters.

Our study confirms previous reports showing that pSS patients have more frequently parotid gland enlargement. ${ }^{46}$ As described by He $e t$ al, we found that patients with SS/RA have more frequently articular and pulmonary involvement. ${ }^{4}$ It is difficult to decipher if articular involvement was linked to RA or to SS in these patients. Of note, in our study, more than $50 \%$ of the RA/SS patients had erosions. Regarding lung involvement, discrimination between SS linked or RA linked manifestations is also challenging. ILD complicating pSS tends to give more NSIP while ILD complicating RA tends to give usual interstitial pneumonia (UIP). In our study, pulmonary involvement seemed to be mainly due to SS in the SS/RA group since there was no UIP.

This study shows that patients with pSS and SS/RA have the same level of systemic disease activity. Thus, in RA patients, sicca symptoms should not be neglected and should be 
Table 1 Comparison of pSS and SS/RA

\begin{tabular}{|c|c|c|c|}
\hline & pSS & SS/RA & $P$ value \\
\hline Number of patients & 124 & 62 & \\
\hline Female sex (n,\%) & 112/124 (90\%) & 49/62 (79\%) & 0.033 \\
\hline Age & $55.06(13,9)$ & $53.55(14,3)$ & 0.539 \\
\hline Disease duration & 8.8 years $(8.8)$ & 8.1 years $(8.8)$ & \\
\hline Tobacco & 19/112 (17\%) & $16 / 55(29 \%)$ & 0.07 \\
\hline Asthenia $(n, \%)$ & 99/122 (81\%) & $35 / 41(85 \%)$ & 0.541 \\
\hline Dry eye $(n, \%)$ & 107/124 (86\%) & 47/56 (84\%) & 0.676 \\
\hline Dry mouth (n, \%) & 111/124 (89\%) & 48/55 (87\%) & 0.660 \\
\hline Others sicca syndrome (vagina and skin) (n, \%) & 90/118 (76\%) & $30 / 51(58 \%)$ & 0.022 \\
\hline Parotid enlargement (n, \%) & 61/123 (49.6\%) & 13/59 (22\%) & $<0001$ \\
\hline Myositis (n, \%) & $1 / 123(1 \%)$ & $1 / 60(2 \%)$ & 0.602 \\
\hline Arthralgia (n, \%) & $61 / 108(56.5 \%)$ & $54 / 62(87 \%)$ & $<0001$ \\
\hline Arthritis (n, \%) & 20/123 (16.3\%) & $57 / 62(92 \%)$ & $<0001$ \\
\hline Peripheral neurological involvement (n, \%) & 10/121 (8.3\%) & $1 / 62(1.6 \%)$ & 0.073 \\
\hline Central neurological involvement $(\mathrm{n}, \%)$ & 2/123 (1.6\%) & $0 / 62(0 \%)$ & 0.313 \\
\hline Pulmonary involvement (n, \%) & 7/123 (5.7\%) & 9/62 (14.5\%) & 0.044 \\
\hline Renal involvement $(\mathrm{n}, \%)$ & $3 / 123(2.4 \%)$ & $0 / 61(0 \%)$ & 0.219 \\
\hline Lymphadenopathy, (n, \%) & 15/123 (12.2\%) & 7/62 (11.3\%) & 0.858 \\
\hline Lymphoma (n, \%) & $9 / 123(7 \%)$ & $2 / 62(3 \%)$ & 0.267 \\
\hline IgG levels (g/L)(Mean (SD)) & $13.6(6.6) / 113$ & $15(4.7) / 45$ & 0.067 \\
\hline Presence of monoclonal peak (n, \%) & 10/114 (9\%) & 7/55 (13\%) & 0.423 \\
\hline CRP (mg/L)(Mean (SD)) & $6.3(6.5) / 112$ & $13.6(23.4) / 61$ & 0.184 \\
\hline ESR (mm at 1 hour)(Mean (SD)) & $23.6(21) / 109$ & $39.7(27.3) / 58$ & $<0001$ \\
\hline Lymphocytes count $\left(/ \mathrm{mm}^{3}\right)($ Mean (SD)) & $1673(1212) / 118$ & $1657(636) / 62$ & 0.494 \\
\hline Beta2-microglobulin (mg/L)(Mean (SD)) & $2.3(1.1) / 101$ & $2.7(1.5) / 39$ & 0.172 \\
\hline LDH (U/L)(Mean (SD)) & $344(101) / 105$ & $350(57.9) / 37$ & 0.344 \\
\hline C3 (g/L)(Mean (SD)) & $1.09(0.3) / 111$ & $1.1(0.3) / 43$ & 0.893 \\
\hline C4 (g/L)(Mean (SD)) & $0.31(0.9) / 111$ & $0.22(0.1) / 42$ & 0.987 \\
\hline Anti-SSA antibodies (n, \%) & $86 / 120(72 \%)$ & $35 / 60(58 \%)$ & 0.072 \\
\hline Anti-SSB antibodies (n, \%) & 48/122 (39\%) & 17/58 (29\%) & 0.19 \\
\hline RF positivity (n, \%) & $57 / 119(48 \%)$ & $54 / 62(87 \%)$ & $<0001$ \\
\hline RF levels when detectable (UI/mL)(Mean (SD)) & $426(794)$ & $348(569)$ & 0.651 \\
\hline Anti-CCP (n, \%) & $1 / 107(1 \%)$ & 55/62 (89\%) & $<0001$ \\
\hline Cryoglobulinemia (n, \%) & $2 / 123(2 \%)$ & $3 / 62(5 \%)$ & 0.203 \\
\hline ESSDAI & $3.74^{5}$ & $6.3(5.5)$ & $<0001$ \\
\hline Cumulative ESSDAI & $6.8(7,5)$ & $9.2(5.7)$ & $<0001$ \\
\hline ESSDAI without joint domain & $2.85(4.8)$ & $3.2(4.8)$ & 0.971 \\
\hline Cumulative ESSDAI without joint domain & $5.4(7.4)$ & $4.5(5.3)$ & 0.573 \\
\hline
\end{tabular}

Variables are presented as mean (SD) or number and percentage.

explored in order to detect an associated SS and to adapt the follow-up accordingly especially concerning pulmonary involvement and risk of lymphoma.

Contributors All of the authors have contributed substantially to the manuscript, agree with the data and the interpretations of the manuscript content, and have given their permission to submit the attached version of the manuscript. None of the authors have conflicts of interest with any aspect of the manuscript. This manuscript has not been published elsewhere and, if accepted in your journal, will not be republished in any other journal in the same or similar form without consent from the Editor of RMD Open.
Funding The authors have not declared a specific grant for this research from any funding agency in the public, commercial or not-for-profit sectors.

Competing interests None declared.

Patient consent for publication Consent obtained directly from patient(s)

Ethics approval This study involves human participants and was approved by local ethic committee Participants gave informed consent to participate in the study before taking part.

Provenance and peer review Not commissioned; externally peer reviewed.

Open access This is an open access article distributed in accordance with the Creative Commons Attribution Non Commercial (CC BY-NC 4.0) license, which 
permits others to distribute, remix, adapt, build upon this work non-commercially, and license their derivative works on different terms, provided the original work is properly cited, appropriate credit is given, any changes made indicated, and the use is non-commercial. See: http://creativecommons.org/licenses/by-nc/4.0/.

ORCID iDs

Nolan Hassold http://orcid.org/0000-0003-0944-4997

Raphaele Seror http://orcid.org/0000-0002-5523-1856

Xavier Mariette http://orcid.org/0000-0002-4244-5417

\section{REFERENCES}

1 Mariette X, Criswell LA. Primary Sjögren's syndrome. N Engl J Med 2018;378:931-9.
2 Nocturne G, Mariette X. Sjögren syndrome-associated lymphomas: an update on pathogenesis and management. $\mathrm{Br} J$ Haematol 2015;168:317-27.

3 Kollert F, Fisher BA. Equal rights in autoimmunity: is Sjögren's syndrome ever 'secondary'? Rheumatology 2020;59:1218-25.

$4 \mathrm{He}$ J, Ding Y, Feng M, et al. Characteristics of Sjogren's syndrome in rheumatoid arthritis. Rheumatology 2013;52:1084-9.

5 Seror R, Ravaud P, Bowman SJ, et al. EULAR Sjögren's syndrome disease activity index: development of a consensus systemic disease activity index for primary Sjögren's syndrome. Ann Rheum Dis 2010;69:1103-9.

6 Moutsopoulos HM, Webber BL, Vlagopoulos TP, et al. Differences in the clinical manifestations of sicca syndrome in the presence and absence of rheumatoid arthritis. Am J Med 1979;66:733-6. 